\title{
Research on the Dimensions of College Students' Entrepreneurial Network Orientation
}

\author{
Zhang Qi $^{1}$ Zhang Minglin ${ }^{1}$ Zeng Lingming ${ }^{2}$ \\ ${ }^{1}$ Business College of Jiangxi Normal University \\ Nanchang, Jiangxi, 330022 \\ ${ }^{2}$ Jiangxi Institute of economic development, Jiangxi Normal University \\ Nanchang, Jiangxi, 330022
}

\begin{abstract}
Network orientation refers to the attitudes and tendencies to utilize social network relations, it has gradually attracted the attention of scholars in the study of entrepreneurship, and most existing researches are from organizational level to explore. In this paper, through the review and summary of the related research literature, extracts the dimensions and measurement indicators of college students at the entrepreneurial level. Then, a quantitative study is conducted using the questionnaire survey method to verify the proposed dimensions and design scales. The results found that the network orientation of college students can be divided into three dimensions: network cooperation, network construction, and network awareness. There are 11 items that can respond to different dimensions. This study is an empirical exploration of the network-oriented approach at the individual level, which enriches the relevant research on individual network orientation and is beneficial to helping and guiding college students to develop and use network relationships in practice.
\end{abstract}

Keywords-Entrepreneurial networks; Entrepreneurs; Network orientation; Dimension test

\section{INTRODUCTION}

Under the upsurge of "Mass entrepreneurship, mass innovation", with the support and advocacy of "Internet +" by the national policy, many small or medium-sized entrepreneurial enterprises have emerged continuously and become an important driving force to promote China's economic development. Among the entrepreneurs, college students have become a new force that cannot be ignored. "Employing entrepreneurship to promote employment" is a broad consensus that has been formed in all sectors of society. College students are the entrepreneurial groups with the most vitality and development potential, all parties are working together to build them into new forces for entrepreneurial development. However, entrepreneurship is a complex process full of opportunities and challenges. Entrepreneurs in the entrepreneurial process, especially in the initial stage, there is an inequality between the needs and access to various resources, must fully utilize the peripheral relationships to obtain entrepreneurship resources that can maintain the smooth implementation of entrepreneurial activities.
From the sociological perspective, the relationship between individuals and individuals constitutes a social network, Mitchell (1969) treats formal and informal relationships as social networks [1]. Compared with ordinary entrepreneurs, college students lack the social qualifications and wealth accumulation when undertaking entrepreneurial activities, the acquisition of entrepreneurial resources depends more on their own social networks. Therefore, the construction, utilization and maintenance of network relationships play a very important role for college students to obtain entrepreneurial resources. In this process, the attitude and tendency of using the network to solve the entrepreneurial practice problem is called network orientation [2]. Domestic scholar Dong Baobao (2015) explored the four dimensions of China's new enterprises' network orientation through qualitative analysis and quantitative analysis, which has been made a useful exploration to network orientation at the organizational level [3]. At present, the problems existing in the research of network orientation in the domestic academic circles are mainly reflected in: 1) The network-oriented dimensions. What are the dimensions of network orientation? The network oriented dimensions exist big differences while divided. 2) Network-oriented research level. Most of the existing researches are based on the organizational level, but less research on individual-level network orientation. 3) Networkoriented situational features. Scholars need to understand the characteristics of network relationships based on contextual factors, but the presentation of network relationships in different contexts is complex.

Under the above realistic and theoretical background, this article attempts to explore the entrepreneurial network orientation of college students. In theory, this paper focuses on the network-oriented behaviors of entrepreneurial college students and conducts empirical research on individual-level network orientation through corresponding measurement models verification, which enriches the entrepreneurs' network orientation theory. In practice, the questionnaire survey of this study can understand their current network relationships and building conditions, which is conducive to use and develop their own networks better 


\section{THEORETICAL REVIEW}

\section{A. The entrepreneurial network}

From the most basic sense, the entrepreneurial network is a collection of groups of objects connected by links. The concept of "social network" was first proposed by Barnes (1954). He used "social network" to refer to informal links except for formal relationship. The essence of a network is a self-centered network (Wassermann \& Faust 1994; Johannisson 1998), its basic structure is a series of nodes and links, they represent different subjects that form connections in the entrepreneurial process [4]. Entrepreneurs in this particular network situation: On the one hand, while making use of social network relations to start businesses, they selectively connect certain network subjects to establish entrepreneurial networks. On the other hand, the entrepreneurs' dynamic behavior also constantly change the structure, functions, and relationships of social networks. Entrepreneurs continue to solve problems such as resource acquisition and lack of legitimacy by means of entrepreneurial networks. Therefore, entrepreneurial networks have a direct impact on the success or failure of entrepreneurial ventures.

For entrepreneurial college students, the individual networks can be seen as start-up resources for entrepreneurship. That is to say, college entrepreneurs must rely on social network relations to adjust resource requirements and acquisitions during the initial stage of entrepreneurship even for a period of time. In this context, the social network of them is the entrepreneurial network. In view of this, this paper explores the college students' entrepreneurial network orientation based on their surrounding social network relationships.

\section{B. Network orientation}

Network orientation is based on the development of social network theory research, which originated from the study of psychology. Tolsdorf (1976) defined the network orientation as the beliefs, tendencies and attitudes of dealing with life issues through network relationships [5]. Due to the importance of dealing with certain issues, network orientation has gradually been cited in various fields. Mizruchi (1994) explained the concept of network orientation from an economic point of view, pointing out that it is an internal behavioral tendency that rational economic people expect to benefit from economic ties; the first to introduce it into the study of management is Barnir. With Smith (2002), they think that network orientation is the tendency of entrepreneurs or managers to build and maintain network relationships; Sorenson et al. (2008) first introduced network orientation into the field of entrepreneurial research, they believe that network orientation is the attitude and tendency of building and maintaining network relationships to solve problems or obtain help for the entrepreneurs or entrepreneurial organizations[2]; domestic scholar Ren Ping (2011) defines network orientation as a cooperative tendency that managers or organizers exhibit when they conduct business activities[6]. In addition, Dong Baobao et al. A lot of research has been done on network orientation. Overall, network orientation emphasizes the thinking, development, and utilization of network value, especially the contextual role of the network, which focuses on using the network to identify new opportunities and acquire new resources in specific situations. At present, there are many defining perspectives on the concept of network orientation, mainly from the perspectives of psychology, sociology, economics, and management, but its connotation focuses on two major aspects: orientation and attitude.

Regarding the network-oriented dimension, different research areas have divided them differently. For example, Yang (1981), a scholar of sociological studies, has proposed three dimensions from the individual perspective: formalization of relations, the interdependence of relations and the harmony of relations [7]; based on management research, Ren Ping (2011) 1 put forward the cooperation, relationship concern, open management of these dimensions from the enterprise level, it's obviously that the analysis of the dimensions of these two perspectives is quite different. The division of Yang mainly reflects the tendency of the individual's choice of operating methods and attitudes toward the network relationship, but Ren Ping's is mainly based on the company's behavior in the network relationship processing, it also shows that the division of network-oriented dimensions is very contextual and do not form a standard division, there are more research is needed to find out. At present, in the field of entrepreneurship, Sorenson et al. (2008) analyzed the network orientation at the individual or organizational level in three dimensions: cooperation dimensions, network construction, and network team construction. Later, Ren Ping and Dong Baobao's related researches can draw lessons from this. The research object of this paper is the group of college students, compared with the general entrepreneurs, their networks have the characteristics of "small" and "weak". "Small" refers to the small scale and low divergence of the overall network. "Weak" refers to the weak network structure and limited resources available. Therefore, the research on network orientation of college students is still not deep enough in academia, that can't explain their network-oriented features. The specific networkoriented dimensions have yet to be developed, which this paper innovation lies.

\section{THE HYPOTHESIS OF NETWORK ORIENTED DIMENSION}

Because of the characteristics of college students' network, combined with their entrepreneurial situation, this study believes that the entrepreneurial network orientation of college students refers to the tendencies, expectations and attitudes that maintain the internal network and the establish network relationship with the external environmental entities when entrepreneurs carry out their entrepreneurial activities. The entrepreneurial perspective of network research focuses more on personal psychology and cognition, focusing on entrepreneurs' personal understanding and understanding of the Internet [2]. Drawing on Sorenson et al. (2008)[8], Ren Ping (2011), Dong Baobao (2015) and others on network-oriented and Chow (2008) research on social network perception[9], combined with the entrepreneur's personal characteristics, this paper believes that the following three dimensions can use to measure college students' entrepreneurial network orientation. 
Network construction: Network construction refers to that entrepreneurs pay attention to the types, construction foundations, and construction costs of networks when building network relationships. Entrepreneurs need to determine the direction of network construction when they consider the value of the network, that is, what types of networks are built. Because college students' social networks (or called) have the "small" and "weak" characteristics on starting their entrepreneurial activities, the construction of network relationships is of great importance in the early period. Not only does network construction do favor of expanding the scale of the network, but also promote the exchange of information in practice to some extent. However, network construction is not blind, entrepreneurs definitely hope to build network relationship that can bring about certain values, especially for college students who need to accumulate contacts and resources. In the process, which type of network should be built, the network foundation of own and what to build the network are all issues to be considered. This is closely linked with the composition of the entrepreneurial network.

Network cooperation: Cooperation emphasizes the communication, exchange and cooperation between entrepreneurs and external network entities, reflecting the fundamental attributes of network orientation. The strong cooperation shows that entrepreneurs have a higher network orientation, which stresses cooperation with external parties to help solve problems and obtain resources. Actively collaborating with them can not only solve some difficulties that entrepreneurial college student at survival and development period faced, but also help them acquire more knowledge and information in their operations. The sharing and use of knowledge resources has important guiding significance to their decision-making process, such as a new technology or a certain channel, which is "precious" and "scarce" for the entrepreneurial college students and can be obtained in a relatively easy way. The cooperation with external network entities enhance their own competitive advantage.

Network perception: Network perception refers to the individual's overall knowledge and understanding of the network and its interaction with network entities. Social network as an individual access to resources and information, a good perception of the network helps entrepreneurs to integrate and operate the network better. The individual's perception of social networks is also an important factor that influences their behavior. Which test and verify the status of the individual's network. Frequent interactions with external network entities are prone to emotional factors such as trust, under such circumstances, sharing of knowledge and resources is more likely to occur. That is, network-aware entrepreneurs acquire information and resources in network relationships more fully, it is obviously very helpful for the smooth development of entrepreneurial activities. Although the development of the network is very important, it takes time and energy for the entrepreneurial college students, but the grasp and maintence of existing networks can't be ignored.

\section{EMPIRICAL ANALYSIS}

\section{A. The determination of network oriented items}

Referring to the measurement scales of network-oriented research conducted by Sorenson et al., Ren Ping, and Dong Baobao, this study has designed 12 tests items based on the assumptions of three dimensions: network construction, network cooperation, and network awareness. The items were pre-tested on a small scale. According to the analysis results of the pre-survey data and the survey respondents' feedbacks, the ambiguous and repetitive questions were removed, and the design of the items was further streamlined. The final test items include three items for network cooperation, four items for network construction, and four items for network awareness.

\section{B. An exploratory factor analysis of network orientation}

Samples and data. In order to verify the validity of the questionnaires obtained in this study, we first need to conduct an exploratory analysis on the questionnaires. This questionnaire survey was conducted for all university students, distributed in the form of electronic questionnaires and paper questionnaires, it was sufficient to retrieve 162 valid questionnaires. From the data, it can be known that about $42.6 \%$ of the males and about $57.4 \%$ of the females are filled in, the highest proportion is in the fourth grade, which accounts for about $30 \%$. The percentage of people who have graduated has added more than $45 \%$, senior fillers have more entrepreneurial experience and kown more about it. In the case of entrepreneurial experience, only about $25 \%$ is filled in. It reflects that the college students have some difficulties in practicing entrepreneurial activities on campus.

Reliability test and exploratory analysis of the scale. The questionnaires used in this study were all measured using the Likert 5 scale. The number of items per factor is more than two, which is also conducive to the improvement of the sensitivity of the questionnaire. The statistical results of SPSS 21.0 statistical analysis software show that the clonal Bach coefficient of each factor is higher than 0.8 , so the scale has a good internal consistency. Then exploratory factor analysis was performed for all items, the KOM value was 0.926 , and the bartlett's test value was also less than 0.05 , indicating that the items in the questionnaire were suitable for factor analysis. Under the condition that the eigenvalue is greater than 1 , the principal component factor analysis after maximizing the orthogonal rotation and after multiple iterations using variance has naturally formed three factors. The factor load critical value takes 0.6 , and the load value is lower than 0.6 or load factors greater than 0.6 on multiple factors are rejected. It was found that each item of the questionnaire was greater than the critical value of 0.6 , no item was deleted, and the remaining 11 items could explain $74.04 \%$ of the variance. The results of the analysis are shown in Table 1. 
TABLE I.

EXPLORATORY FACTOR ANALYSIS OF NETWORK ORIENTED MEASURE INDEX

\begin{tabular}{|c|c|c|c|}
\hline \multirow{2}{*}{ Items of network orientation } & \multicolumn{3}{|c|}{ load of factors } \\
\hline & 1 & 2 & 3 \\
\hline \multicolumn{4}{|l|}{ Network cooperation (Cronbach's Alpha $=0.904)$} \\
\hline V1: Entrepreneurs often communicate with external networks to promote certain issues & 0.752 & & \\
\hline $\begin{array}{l}\text { V2: Entrepreneurs often communicate with external networks to identify valuable } \\
\text { opportunities }\end{array}$ & 0.841 & & \\
\hline $\begin{array}{l}\text { V3: Entrepreneurs often communicate with external networks to exchange resources for each } \\
\text { other }\end{array}$ & 0.853 & & \\
\hline \multicolumn{4}{|l|}{ Network construction (Cronbach's Alpha $=0.855)$} \\
\hline $\begin{array}{l}\text { V4: Entrepreneurs take an active interest in the categories of network construction when } \\
\text { building }\end{array}$ & & 0.633 & \\
\hline V5: Entrepreneurs understand the foundation of network construction when building & & 0.779 & \\
\hline V6: Entrepreneurs actively construct external networks when building & & 0.689 & \\
\hline $\begin{array}{l}\text { V7: Entrepreneurs value networking and pay attention to the cost of construction and } \\
\text { maintenance }\end{array}$ & & 0.818 & \\
\hline \multicolumn{4}{|l|}{ Network perception (Cronbach's Alpha $=0.869$ ) } \\
\hline $\begin{array}{l}\text { V8: Entrepreneurs believe that the relationship with most external network entities remains } \\
\text { good }\end{array}$ & & & 0.614 \\
\hline $\begin{array}{l}\text { V9: Entrepreneurs believe that they have maintained close contact with most external } \\
\text { network entities }\end{array}$ & & & 0.637 \\
\hline $\begin{array}{l}\text { V10: When faced with a problem, entrepreneurs can discuss and solve problems with certain } \\
\text { network entities }\end{array}$ & & & 0.804 \\
\hline $\begin{array}{l}\text { V11: Entrepreneurs can clearly understand the relationship with various network entities and } \\
\text { take maintenance measures }\end{array}$ & & & 0.627 \\
\hline Eigen value $(>1)$ & 3.404 & 2.816 & 2.665 \\
\hline Variance explained (accumulated \%) & 28.367 & 51.831 & 74.039 \\
\hline
\end{tabular}

Confirmatory factor analysis. Since the scale itself was designed with reference to the mature scale developed by other scholars, and the collected data was analyzed with good reliability, this study used AMOS21.0 software performs confirmatory factor analysis after exploratory factor analysis. The specific results are shown in Figure 1, the fitting indicators are shown in Table 2. From the results of confirmatory factor analysis, the network-oriented hypothesis model of this study has a good degree of fitness. This shows that the networkoriented measures of each dimension can cover the basic information of the content of the measure to a certain extent, the network-oriented variable has certain explanatory power. Broewne and Gudec (1989) believe that the normalized factor load values and their significance in the structural equations are used to determine the convergence validity of the scale, and each value should be greater than the critical value of 0.6[10]. Figure 1 shows that the load values of each item on the respective factors are greater than 0.6 , indicating that the scale has convergence. 


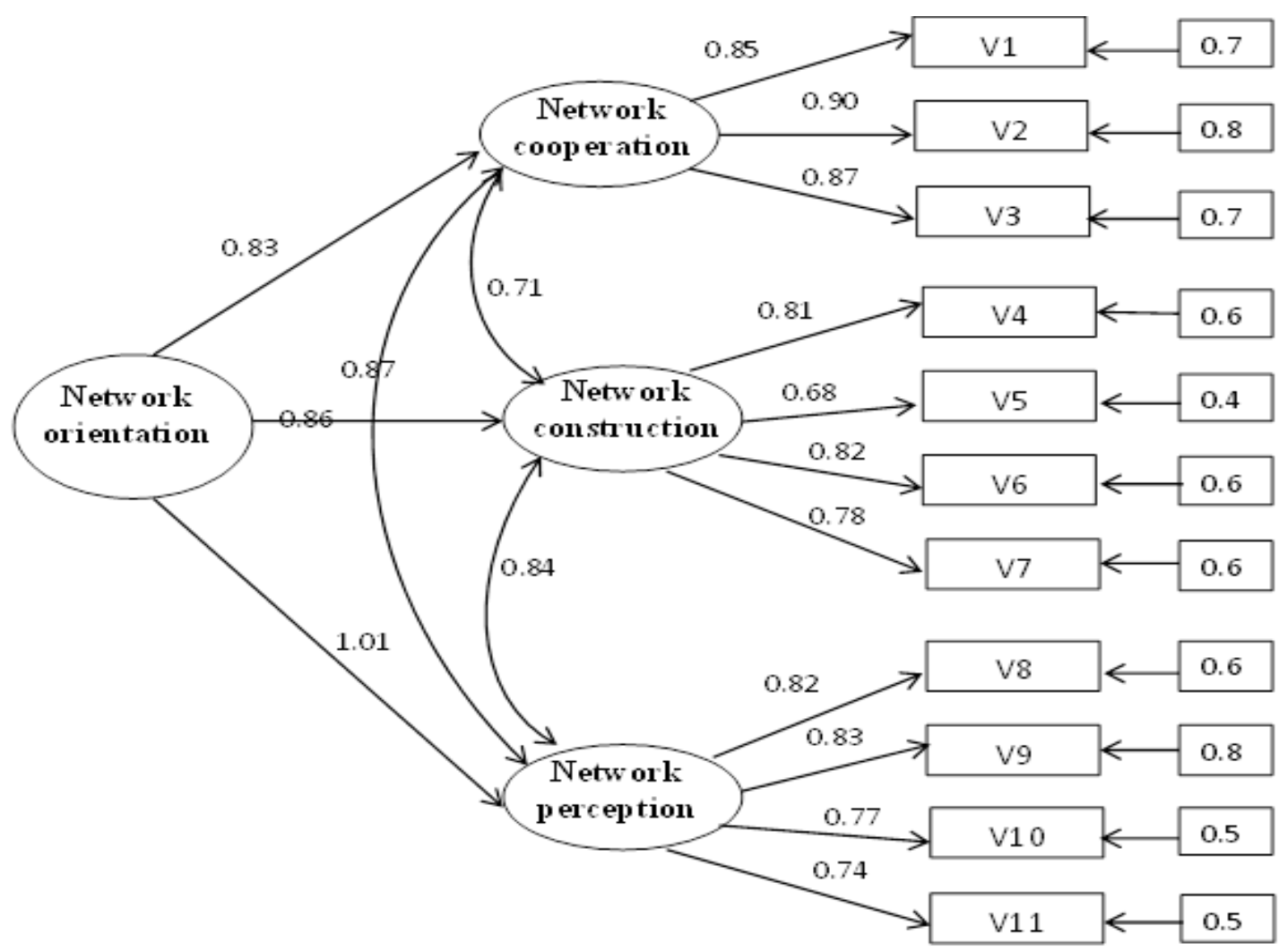

Fig. 1. Validation Factor Analysis of Network Orientation Measurement Model

TABLE II. NETWORK ORIENTED MODEL FITTING INDEX

\begin{tabular}{|c|c|c|c|}
\hline & Fit index & Numeric values & Fitting numerical index \\
\hline \multirow{3}{*}{ Absolute index } & $\chi^{2}$ & 88.456 & - \\
\cline { 2 - 4 } & $\mathrm{df}$ & 41 & - \\
\cline { 2 - 4 } & GFI & 0.912 & $>0.90$ \\
\cline { 2 - 4 } & RMSEA & 0.08 & $<0.08$ \\
\hline \multirow{3}{*}{ Relative index } & IFI & 0.961 & $>0.90$ \\
\cline { 2 - 4 } & NFI & 0.930 & $>0.90$ \\
\cline { 2 - 4 } & RFI & 0.906 & $>0.90$ \\
\cline { 2 - 4 } & CFI & 0.961 & $>0.90$ \\
\hline
\end{tabular}

\section{CONCLUSION}

On the basis of theoretical analysis and literature review, this study explores the network-oriented behavior of college students in the context of entrepreneurship, and proposes three dimensions of network cooperation, network construction, and network awareness as well as verify it. Firstly, preinvestigation was conducted to revise the proposed question, and then began to collect sample data. The proposed threedimensional hypotheses were verified by exploratory factor analysis and confirmatory factor analysis. The results showed that the three dimensional hypotheses passed. Validation shows that these three dimensions can explain the network-oriented behavior of undergraduate students in the context of entrepreneurship to some extent. Due to the lack of research on the individual-level network orientation in the current research field, this study is only an exploratory study in this area. Therefore, possible deficiencies are: (1) Account for time and geographical constraints, the sample data collection is low. And the distribution scope is not broad enough, and multi-level data samples can better explain the commonalities of the network-oriented behavior of the group, and the analysis results are more representative; (2) The specific impact items in some dimensions are not sufficiently accurate, and due to differences in groups and cultures, the results of the research are not applicable in every place and every field. In general, the scale designed by this paper is good for the hypothesis testing effect. It analyzes the connotation and dimensions of university 
students' entrepreneurial network orientation, and provides direction and reference for future personal orientation research.

\section{REFERENCES}

[1] Mitchell, Clyde J. Social networks in urban situations: [M]. Published for the Institute for Social Research, University of Zambia, by Manchester U.P. 1969.

[2] Dong Baobao.Network orientation of new ventures in china:dimensions and test [J]. Foreign Economics \&Management ,2015 , 37(05):3-13.

[3] Personal networks in emerging knowledge-based firms: Spatial and functional patterns. Johannisson,B. Entrepreneurship Theory and Practice. 1998.

[4] Tolsdorf . Social networks,support, and coping: an exploratory study[J]. Family Process, 1976, 15(4): 407.

[5] Ren Ping. Study on the relationship among network orientation, resource intrgration and corporate performance of the new ventures [D]. Jin Lin University, 2011.

[6] KuoShu Yang. Social Orientation and Individual Modernity among Chinese Students in Taiwan[J]. Journal of Social Psychology, 1981, 113(2):159-170.

[7] Dong Baobao, Zhou Xiaoyue. Network Orientation:Concept explanation, research context and model building[J]. Foreign Economics \& Management, 2016, 38(03):30-43.

[8] Social network, social trust and shared goals in organizational knowledge sharing $[\mathrm{J}]$. Wing S. Chow,Lai Sheung Chan. Information \& Management. 2008 (7).

[9] M.W. Browne, R. Cudeck. Single Sample Cross-Validation Indices for Covariance Structures [J]. Multivariate Behav Res, 1989, 24(4):445-455. 